\title{
The influence of mercury content on the structural changes of bioindicator surfaces
}

\author{
Małgorzata Iwona Szynkowska, Aleksandra Pawlaczyk \\ Technical University of Łódź, Department of Chemistry, Institute of General and Ecological Chemistry, Żeromskiego 116, \\ 90-924 Łódź, Poland
}

\begin{abstract}
This work examines the recommended chemical analytical method for the identification and detecting mercury from the environmental media. The aim of this study was to establish a correlation between mercury content in different biological indicators like: human hair, mushrooms, lichen, moss and needle samples, and the changes in the structure of the investigated material. We have explored the possibilities of using the SEM method in environmental studies to investigate a variety of biological samples coming from areas at different pollution state. We have combined the information from the quantity measurements with the qualitative analysis. The total content of $\mathrm{Hg}$ was determined using the Automatic Mercury Analyzer SP-3D. The accuracy of the applied method was verified by an analysis of proper certificate materials: Mixed Polish Herbs INCT-MPH-2, Lichen CRM 482, Pine needles 1575a and Human Hair NCS ZC 81002. The obtained results proved a direct influence of the content of mercury and environmental pollution on the damage of the structure of the studied samples.
\end{abstract}

Keywords: mercury, surface analysis, bioindicators, SEM.

Presented at VII Conference Wasteless Technologies and Waste Management in Chemical Industry and Agriculture, Międzyzdroje, 12 - 15 June, 2007.

\section{INTRODUCTION}

Unfortunately, each organism exhibits its sensitiveness to mercury toxic effect. For that reason it makes difficult to predict the toxic thresholds for mercury in various biological indicators. Probably the most significant and well-known feature of the impact of $\mathrm{Hg}$ on the environment is its incredible ability to build up in the organisms and along the food chain. However, it should be pointed out that all the forms of mercury can be accumulated by indicators, but organic compounds are preferable and taken up to a higher extent ${ }^{1,2,3}$. During the last few decades many reports and reviews, dealing with the toxicity of mercury and its compounds, including the monographs on mercury ${ }^{4}$, methylmercury ${ }^{5}$ and mercury-environmental aspects ${ }^{6}$, have been published. Also a huge amount of data on mercury content in different environmental components (air, water, sediments, soil) and biota (living organisms, human, plants, animals) has been presented in the literature. The latest programs of campanies and reports confirmed the international global interests to initiate the activities supporting the actions regarding and preventing mercury pollution $^{1,7,8}$. The global actions consider two main goals connected with the identification of exposed areas and populations and the reduction of mercury release influencing the state of environment and human health. With regard to a long-term future action and in response to UNEP (United Nations Environment Programme) The Governing Council report activities will be undertaken, concerning other heavy metals like $\mathrm{Pb}$ and $\mathrm{Cd}$. It should create a strategic approach to the global management of toxic substances and elements ${ }^{\mathbf{1}, \mathbf{8}}$. Generally, inorganic mercury is not considered as a basic source of effects in the soil compartment. It is caused by the fact that $\mathrm{Hg}$ is bonded to the soil particles and its bioavability to plants is not very high. Gaseous mercury is much more efficiently absorbed by leaves or mosses, through the air, than the exemplary uptake of mercury from the soil by roots. As a result, the major pathway of mercury exposure in the case of plants is through the air. It is worthwhile to mention that the largest single source of mercury pollution is the coal-burning power plant ${ }^{1,9}$.

The detailed information about surface chemistry can be obtained by the scanning electron microscope method. The SEM technique allows studies of morphology of various samples. It is one of the widely applied methods for surface analysis. SEM is generally a relatively rapid technique, it is not destructive to the sample under investigation and can provide the basis for performing an analysis on different fields and aspects. Recently it has been commonly used in environmental studies ${ }^{10}$. This paper is connected with establishing the effect of $\mathrm{Hg}$ concentrations, caused especially by power plants, on the damage of the structure and the accumulation degree of the selected bioindicators.

\section{MATERIAL AND METHODS}

All sampling sites were located in Lódź (city in the central Poland) region. The analyzed material consists of the samples of different groups of bioindicators such as hair, mushroom, needle, moss and lichen samples. The content of the total mercury was measured with the Mercury Analyzer MERCURY SP-3D, Nippon Instrument Corporation. The scanning electron microscopy Hitachi S-4700 was used to depict the differences among the structures of the investigated biological samples, influencing their accumulation abilities and possibly to confirm the changes of their surface, connected with the state of environmental pollution. Hair samples were taken from the people studying in the area of Łódź at two departments: Faculty of Chemistry and Faculty of Mechanical Engineering. The subjects were also asked to fill in a questionnaire concerning the weekly fish consumption or a total number of dental amalgamates. These factors may considerably influence the mercury content in the hair. In order to obtain the information about other factors affecting mercury concentration in the hair we analyzed the content of this toxic metal, collected from a group of children from Lódź and the students from Japan. Approximately $200-300 \mathrm{mg}$ of hair samples, 
including only the first $3-4 \mathrm{~cm}$ closest to the scalp were collected from the nape of the neck, using stainless steel scissors. The samples before an analysis were washed separately with acetone, water and again with acetone (according to the procedure recommended by the International Atomic Energy Agency $^{11}$ ). Mushroom samples of two species Macrolepiota procera, Suillus granulatus were collected at the forest sites located in Łódź region, which were situated far away from any pollution sources, like plants or high-density traffic roads. The samples were divided into caps and stalks, carefully handcleaned to remove the attached soil and dirt particles, rinsed in deionized water and finally homogenized using an agate mortar $^{\mathbf{1 2}}$. Needles of four coniferous trees: fir, pine, spruce, thuja (e.g. Abies alba, Pinus sylvertris, Pinus migra, Pinus resinosa, Picea fabies, Picea mariana, Thuja orientalis, Thuja occidemtalis), moss (Hypnum cupressiforme, Orthodicranum montanum, Pleurozim scherebi) and lichen (e.g. Physica adscendens, Hypogymnia physodes, Evernia prunastri) samples were collected on the territory of Łódź, mainly near traffic roads and in the surroundings of three power plants: EC-2, EC-3, and EC-4 (taken at different distances from the power plants), however, at least $100 \mathrm{~m}$ away from the main roads. Moss samples were taken approximately $5 \mathrm{~m}$ from the nearest tree to avoid the effect of rainwater dripping from the tree crowns throughfall ${ }^{13}$. Lichen samples were taken from the side of the trunks of different tree species trees, not affected by the steam flow, $1.5 \pm 2.0 \mathrm{~m}$ above the ground ${ }^{9}$. Needles were taken from branches at the lower and middle crown ${ }^{14}$ involving the previous-year needles $(\mathrm{C}+1$ needles), and twoyear needles ( $\mathrm{C}+2$ needles). Additionally, the samples of the investigated bioindicators were collected from the background station in the Łagiewniki Forest- chosen to represent the control place. This reference place is one of the biggest forest areas in Poland and Central Europe, which is located on the territory of the city. Additionally, some needles samples were also taken from the places in Poland, strongly affected by industrial activity, like Katowice. Before the measurements the samples were carefully hand-cleaned and homogenized with the agate mortar. In this study the biological samples
Table 2. An average concentration of mercury concentrations for two groups of students: Faculty of Chemistry and Faculty of Mechanical Engineering. Additionally, we have also investigated a group of children and students from Japan, consuming a significant amount of raw fish. (A - average content, F female, $\mathrm{M}-\mathrm{men})\left[{\left.\mathrm{ng} \cdot \mathrm{g}^{-1}\right]}^{-1}\right.$

\begin{tabular}{|c|c|}
\hline \multicolumn{2}{|c|}{ Mercury concentration in hair samples [ng g } \\
\hline Investigated group & $\begin{array}{c}\text { Average concentration of } \\
\text { mercury }\left[\mathrm{ng} \mathrm{g}^{-1}\right]\end{array}$ \\
\hline Faculty of Chemistry & A- 294,0; F-161,5; M- 425,5 \\
\hline $\begin{array}{c}\text { Faculty of Mechanical } \\
\text { Engineering }\end{array}$ & A- 168,4; F- 166,2; M- 170,2 \\
\hline Students from Japan & A- 2209,2; F-; M- 2209,2 \\
\hline Children & A- 153,0; F- 82,0; M- 224,0 \\
\hline
\end{tabular}

were not washed. Cleaning of that kind of biological samples is generally not recommended. It could even cause a damage of the tissues and as a result release endogenous elements ${ }^{\mathbf{1 5}}$. The accuracy of the applied method was verified by an analysis of proper certificate materials of Pine Needles 1575a, Lichen CRM 482, INCT-MPH-2 Mixed Polish Herbs and Human Hair NCS ZC 81002 and a satisfactory agreement was achieved between the certificate values and the obtained results (Table 1).

The aim of this study was to evaluate whether there were any differences in mercury concentrations among the investigated biological indicators and to assess if the state of environmental pollution can considerably affect the changes of the structure of indicators. Other objectives were to determine the relation between the quantity and morphology analysis and make an attempt to explain potential reasons of different accumulation ability.

\section{RESULTS AND DISCUSSION}

In our study average concentrations of $\mathrm{Hg}$ in hair samples were higher in the case of the students from the Faculty of Chemistry than the Faculty of Mechanical Engineering (Table 2). It could be attributed to the differences in potential exposure to chemicals affecting metals content in hair. However, the highest amount of mercury was recorded for the students

Table 1. The results from the measurements of the certificate reference materials $\left[\mathrm{ng}^{-1} \mathrm{~g}^{-1}\right]$, (U-uncertainty)

\begin{tabular}{|l|c|c|c|}
\hline \multicolumn{1}{|c|}{ Results for the certificate reference materials [ng g-1] } \\
\hline \multicolumn{1}{|c|}{ Certificate Material } & Certificate \pm U [ng g & Experimental \pm RSD [ng g \\
\hline Herbs INCT-MPH-2 & $17,6 \pm 1,6$ & $18,2 \pm 0,5$ \\
\hline Pine Needles 1575a & $39,9 \pm 0.7$ & $39,3 \pm 0,5$ \\
\hline Lichen CRM 482 & $480 \pm 20$ & $469 \pm 13$ & 103,4 \\
\hline Human Hair NCS ZC 81002 & $1060 \pm 28$ & 98,50 & 97,71 \\
\hline
\end{tabular}

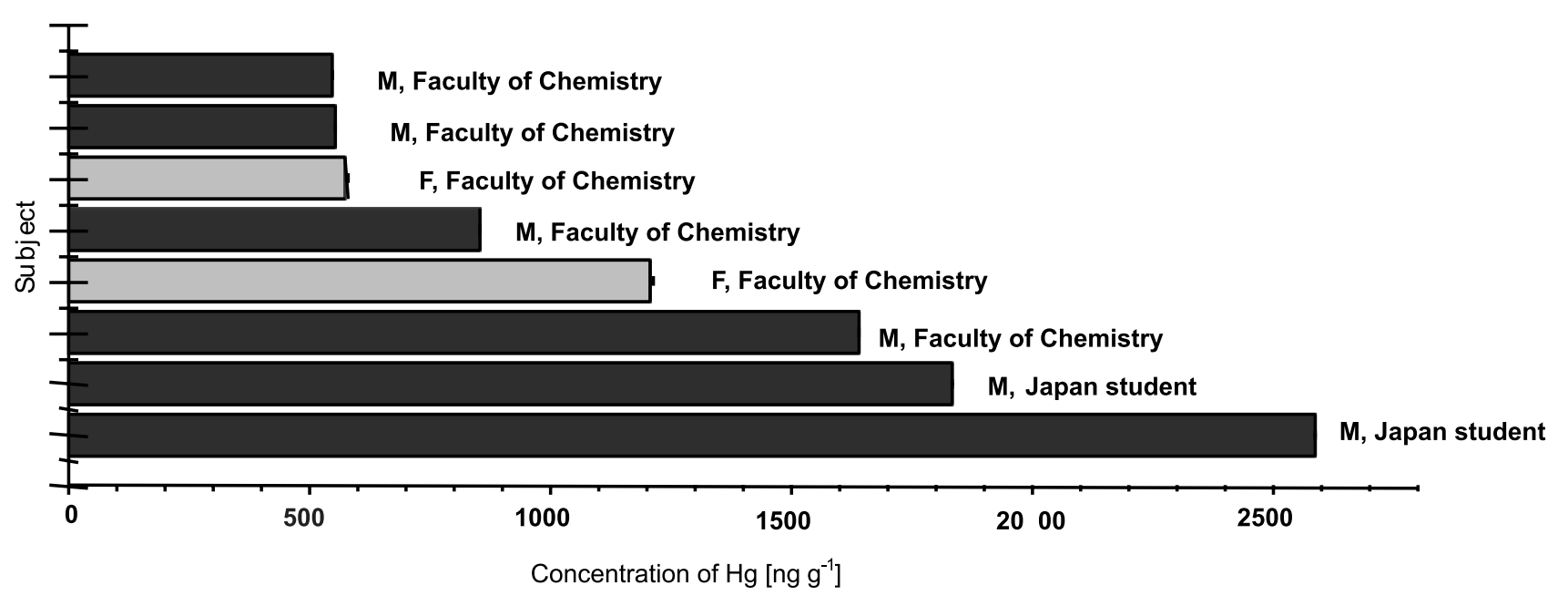

Figure 1. The highest chosen recorded concentrations of $\mathrm{Hg}$ in individuals $\left[\mathrm{ng}^{-1} \mathrm{~g}^{-1}\right]$ 
from Japan, participating in a six-month move semester. The mercury content in the hair of the Japanese people in every case exceeded the recommendable maximum concentrations of mercury in human hair amounted $0,5 \mathrm{mg} / \mathrm{kg}^{16}$. The possible explanation is connected with the diet. Japanese people consume a lot more meals of fish per week, contrary to other studied groups. It is generally well known that most of the retained mercury in our organisms originates from the consumption of seafood and fish and less from dental amalgamates. The lowest amount of $\mathrm{Hg}$ was noticed for the youngest investigated group - children. In general, higher concentrations of mercury were observed for males (Fig. 1). In order to determine a possible linear relation between the numbers of dental amalgamates and the weekly fish consumption, we calculated correlation coefficients. The regression coefficients were in both cases very low (Fig. 2). The lack of linear con-
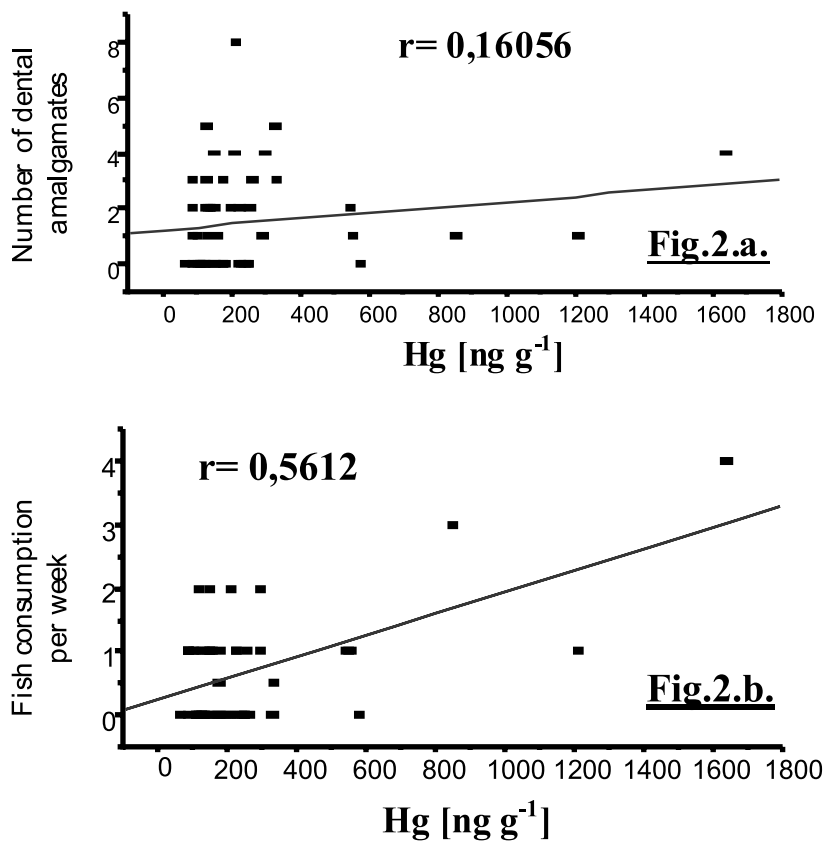

Figure 2. Mercury concentrations in human hair in relation to a number of dental amalgamates (Fig.2.a.) and weekly fish consumption (Fig.2.b.)

nection in our study could be caused by a small number of the investigated subjects (60). Figure 3 presents the SEM images of the chosen samples, accumulating $\mathrm{Hg}$ to the highest and the lowest extent. We can observe the changes of hair structure, which may be connected, among other major factors, with the elevated exposure to this toxic metal. An important difficulty in the application of hair as a bioindicator is the problem of contamination and weak knowledge about the mechanisms of uptake and binding of trace elements in the hair matrix.

Average concentration of $\mathrm{Hg}$ in the case of Suillus granulatis was in every case, beyond the statutory limit (Table 3 ). The maximum admissible content of mercury in dried mushroom is $500 \mathrm{ng} \mathrm{g}^{-1} \mathbf{1 7}$. Thus, that mushroom species does not seem to be hazardous to humans. The opposite situation is observed for Macrolepiota procera. Mercury content in the mushrooms
Table 3. Average $\mathrm{Hg}$ concentrations in fruiting bodies (M), stalks (S) and caps (C) [ng.g ${ }^{-1}$ dry matter]

\begin{tabular}{|c|c|}
\hline Mercury concentrations in mushrooms [ng g & -1 \\
\hline Mushroom & Average concentration [ng g-1] \\
\hline Suillus granulatus & M- 174,$14 ;$ S- 79,$529 ;$ C- 268,75 \\
\hline Macrolepiota procera & M- 7761,2; S- 5659,$8 ;$ C- 9862,5 \\
\hline
\end{tabular}
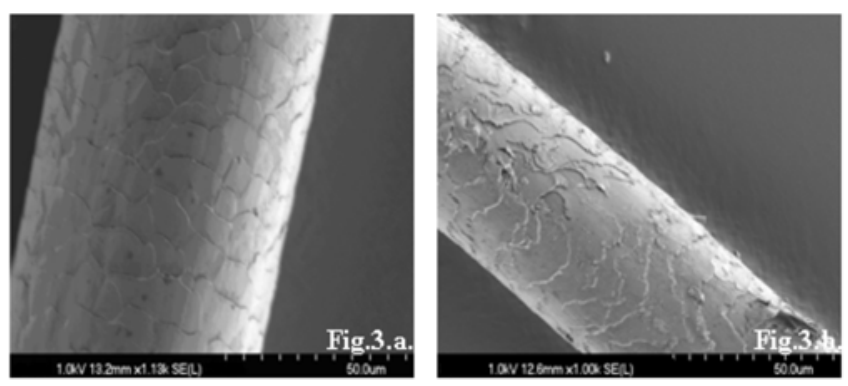

Figure 3. The SEM image of hair surfaces accumulating mercury to the lowest (Fig.3.a., x1100) and the highest extent (Fig.3.b., x1000)

of that species generally exceeded the statutory limits by many times. For the individual sample's concentration of $\mathrm{Hg}$ was even 80 times higher than the maximum permissible level. As a result, the consumption of that mushroom species may present a potential risk to human health. What is more, we have noticed a following tendency: in general, caps accumulated $\mathrm{Hg}$ to a higher extent than stalks (Fig. 4). We have also calculated the correlation coefficient to check if there exists a linear correlation between mercury content in the caps and stalks of the investigated mushroom species. The regression coefficients were in both cases very similar and close to the 0,9 value. Basing on these results we cannot state the presence of a straight linear relation, however an existence of a relation between $\mathrm{Hg}$ concentrations and different parts of mushroom may be observed. The SEM images of stalks and caps may help to explain the quantitative results (Fig. 5). Analyzing the micrographs we can suspect better accumulation ability of Macrolepiota procera (Fig. 5a, b) caused by greater diversity and porosity of its surface. It probably makes it easier to absorb $\mathrm{Hg}$ from the environment, contrary to a less varied and porous structure of Suillus granulatus (Fig. 5c, d).

Samples of mosses, lichens and needles were collected at the same time from the same sampling sites. The results clearly show different bioaccumulation abilities of the studied biological indicators (Table 4). Lichens can be considered as the most suitable indicator for mercury assessment. According to our research, mosses, which generally retain more heavy metals than thalli of lichens, turned out to be a less effective accumulator of mercury. It is in agreement with the literature data9. The authors suggested that lichens are able to take up atmophile elements, like $\mathrm{Hg}$ to a higher extent in contrast to mosses. From all the analyzed bioindicators, the needles samples exhibited significantly lower mercury concentrations (Fig. $6)$. The differences in $\mathrm{Hg}$ levels among four investigated coniferous trees were not statistically important. However, pine needles appear to accumulate the highest amount of mercury. On the other hand, the results for needles were more or less

Table 4. An average concentration of mercury, including the max. and min. obtained values in the investigated bioindicators $\left[\mathrm{ng} \cdot \mathrm{g}^{-1}\right]$

\begin{tabular}{|c|c|c|}
\hline \multicolumn{3}{|c|}{ Mercury concentration in different types of biological indicators [ng g ${ }^{-1}$ ] } \\
\hline Bioindicator & Average content $\left[\mathrm{ng} \mathrm{g}^{-1}\right]$ & Range \pm RSD $\left[\mathrm{ng} \mathrm{g}^{-1}\right]$ \\
\hline Needle & Pine:30,11; Fir:22,46; Spruce:28,68; Thuja:22,60 & $21.00 \pm 0.83-44.07 \pm 2.32$ \\
\hline Moss & 76,00 & $50.06 \pm 0.95-95.53 \pm 2.53$ \\
\hline Lichen & 103,4 & $69.43 \pm 3.21-163.85 \pm 4.56$ \\
\hline
\end{tabular}




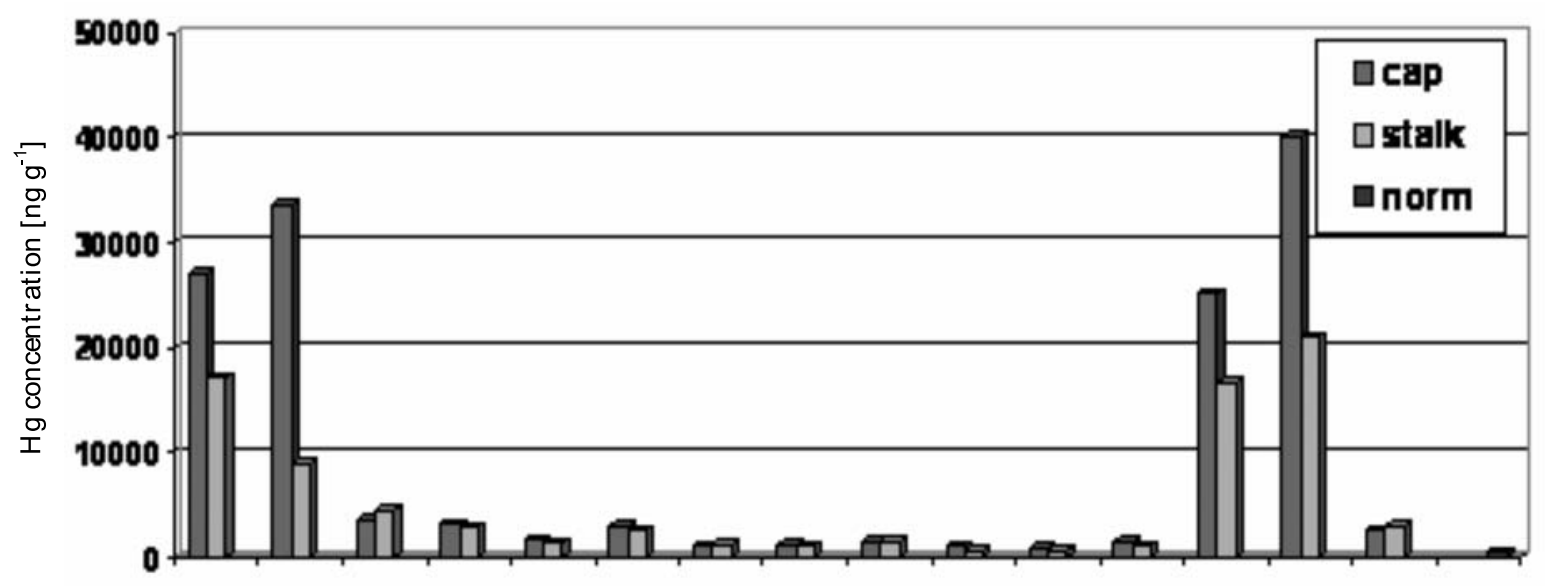

Suillus granulatus

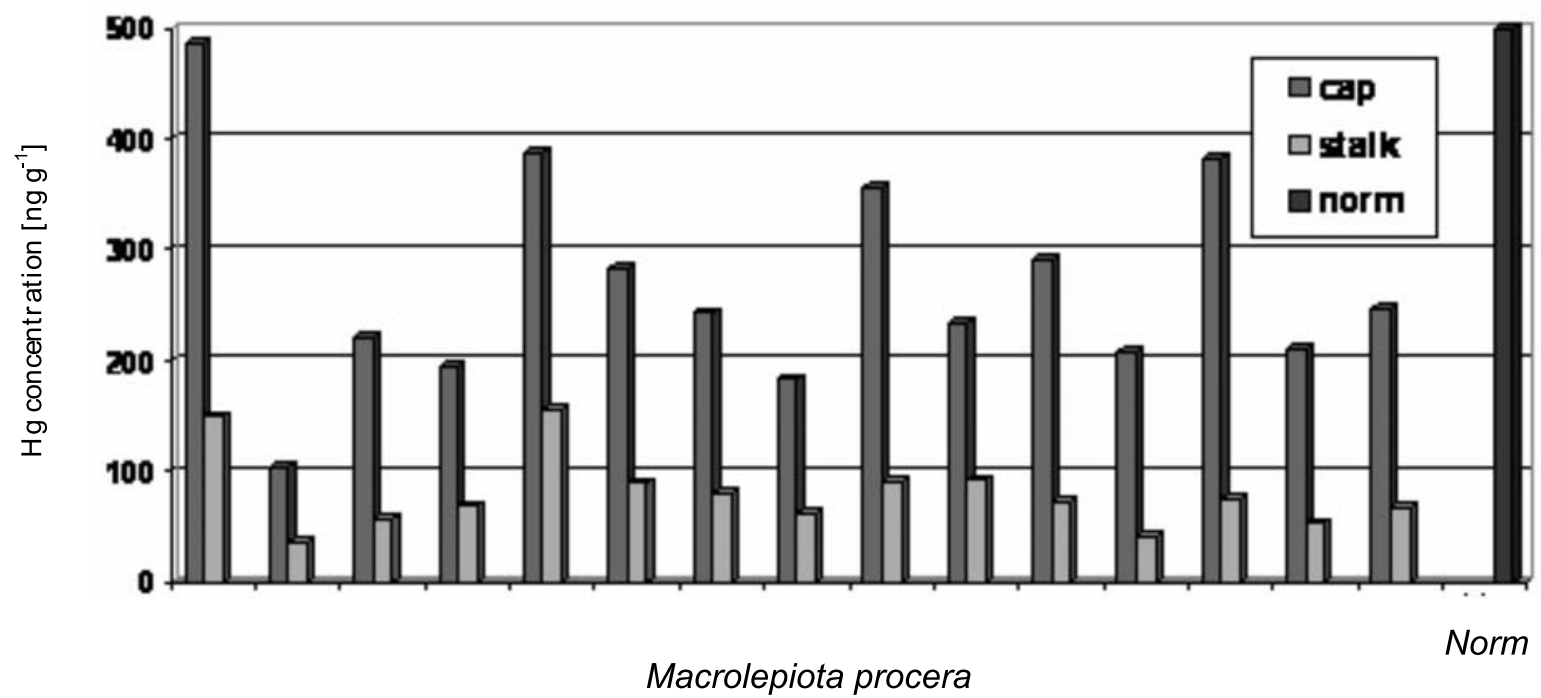

Figure 4. Mercury concentrations in stalks and caps in $S$. granulatus and $M$. procera $\left[\mathrm{ng}^{\circ} \cdot \mathrm{g}^{1}\right]$

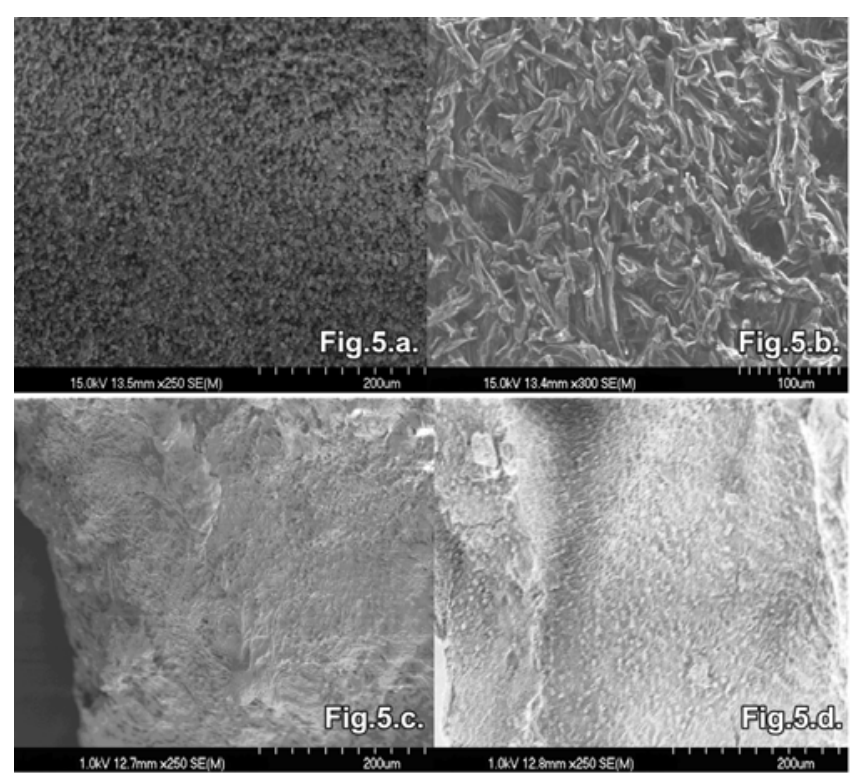

Figure 5. The SEM image of the cap (Fig.5.a., x250) and stalk (Fig.5.b., x300) surface of Macrolepiota procera and cap (Fig.5.c., x250) and stalk (Fig.5.d., x250) surface of Suillus granulatus

comparable. In order to confirm the existence of a linear relation among mercury concentrations in the investigated biological indicators, collected from the same sampling sites, we also calculated the correlation coefficients. The regression coefficients were in each case close to value 1 , which clearly suggests a connection of mercury atmospheric deposition with accumulation by different indicators. In general, we can state that the places most affected by $\mathrm{Hg}$ contamination are connected with the centre of Łódź (traffic contribution to pollution sources of $\mathrm{Hg}$ ) and in the surroundings of three power plants. Surprisingly, the bioindicators, which accumulate the lowest mercury concentrations, had the most degraded structure. These results indicate that needles can be successfully applied as reacting indicators, while mosses and lichens are preferable as better accumulating indicators. The SEM images of the samples, chosen on the basis of the highest and lowest $\mathrm{Hg}$ concentrations, showed significant changes of their micromorphology connected with mercury retaining (Fig. 7). In the case of lichens and mosses, the degradation of their structure was incredibly difficult to define precisely. It is generally caused by a huge diversity of their structure. Undoubtedly, the samples collected from the highly polluted places (with the highest Hg content) have a lot of airborne particles present on their surfaces in contrast to the needles samples. We observed a significant correlation between the wax quality and $\mathrm{Hg}$ content of the needles. Needles taken from places close to sources of $\mathrm{Hg}$ (like power plants) showed a considerably poorer wax quality, their perspirant apparatus was blocked by dust participles, the structure was degraded, rich in many fissures and cracks. The needles collected from the reference site presented untouched wax surface with a clearly marked perspirant apparatus, regulating their inhalatory system. 


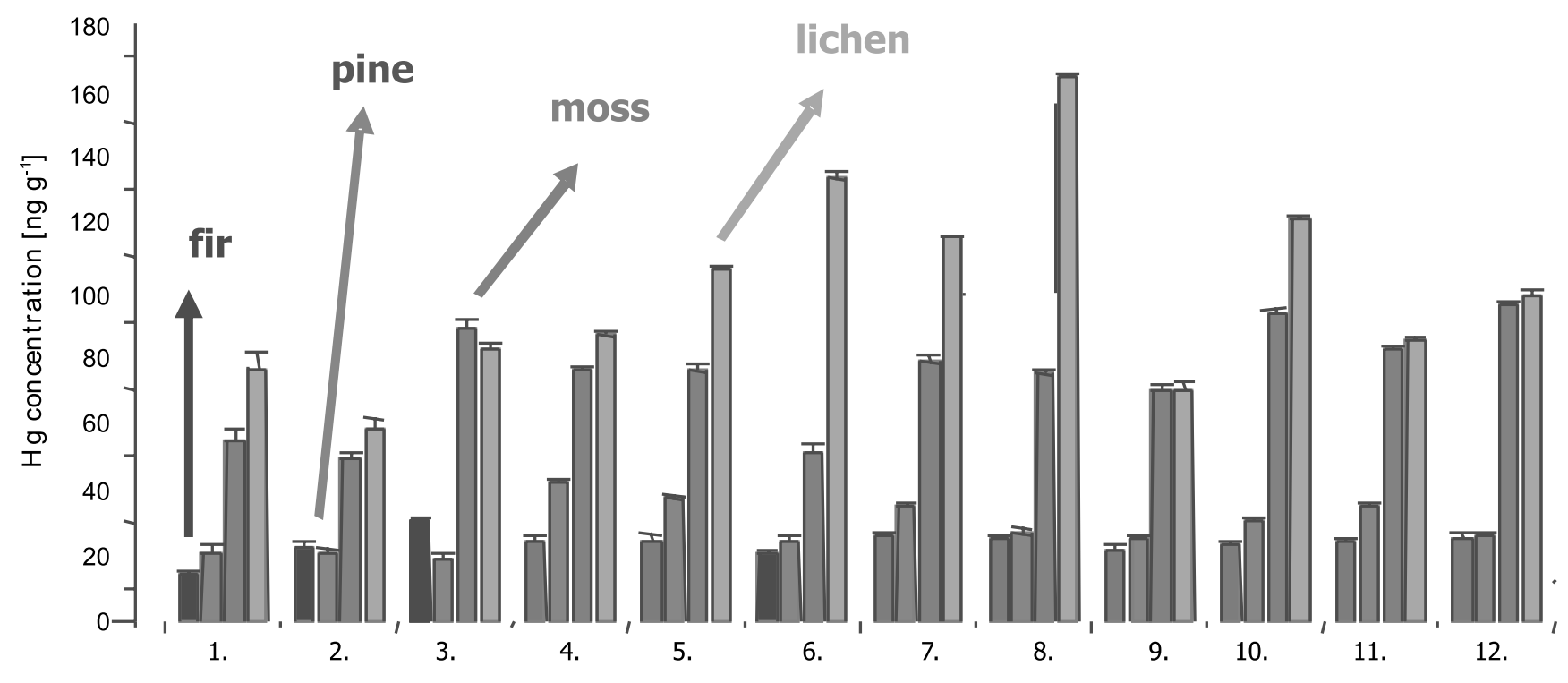

Sampling site

Figure 6. The selected results of mercury concentrations in different bioindicators [ng·g-1 ${ }^{-1}$, where: 1 - Łagiewniki, 2 - Giżycko, 3 - Mickiewicza Park (centre of Łódź), 4 - Poniatowskiego Park (centre of Łódź, intense traffic), 5 - Łódź-Kaliska Station (centre of Łódź), 6 - Popiełuszki Street (suburb of Łódź), 7 - Rzgowska Street (intense traffic), 8 - • ródliska Park (centre of Łódź, intense traffic), 9 - EC-3 (surroundings of one of the power plant), 10 - Śledzia Park (centre of Łódź, high traffic), 11 - EC-4 (surroundings of one of the power plant), 12 - EC-2 (surroundings of one of the power plant)
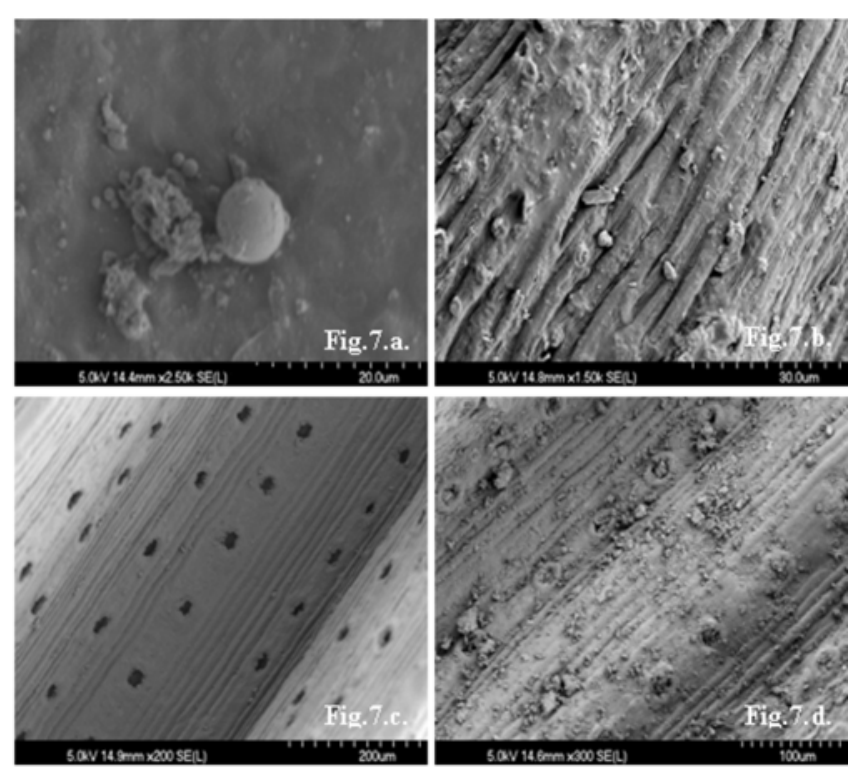

Figure 7. The SEM image of lichen surface collected from the polluted EC-3 (Fig.7.a., x2500), moss surface taken from the polluted EC-4, (Fig.7.b., x1500) and pine needle surface collected from the unpolluted Łagiewniki (Fig.7.c., x200) and the pine needle surface taken from EC-4 (Fig.7.d., x300)

\section{CONCLUSIONS}

Nowadays there is an increasing need for studies focusing on exposure assessment connected with toxic substances. Our study regards the problems associated with evaluating a possible risk of elevated mercury accumulation. The results can prove an existence of a direct relation between the quantitative analysis and the morphology of some selected biological indicators. The investigated materials absorb $\mathrm{Hg}$ to a different degree and mercury accumulation depends on many factors. The SEM methods turned out to be a useful and complementary technique, successfully applied in many cases to confirm the quantitative mercury results.

\section{ACKNOWLEDGEMENTS}

The financial support of this work by the Polish Scientific Research Council (grant N207 075 31/3611) is gratefully acknowledged.

\section{LITERATURE CITED}

(1) United Nations Environment Programme Issued by UNEP Chemicals, Global Mercury Assessment report, Geneva, Switzerland, 2002.

(2) Schroeder W. H., Munthe J.: Atmospheric mercury an overview, Atmospheric Environment, 1998, 5, 809.

(3) Eustace D. J., Walters M., Riley S., Anderson M.: Chemical Health \& Safety, 2004, May/June, 17.

(4) WHO/IPCS, Mercury - Environmental aspects. Environmental Health Criteria No 86, World Health Organisation, International Programme on Chemical Safety (IPCS), Geneva, Switzerland, 1989.

(5) WHO/IPCS, Methylmercury. Environmental Health Criteria No 101, World Health Organisation, International Programme on Chemical Safety (IPCS), Geneva, Switzerland, 1990.

(6) WHO/IPCS, Inorganic mercury. Environmental Health Criteria No 118, World Health Organisation, International Programme on Chemical Safety (IPCS), Geneva, Switzerland, 1991.

(7) US EPA, Mercury study report to congress. US EPA, 1997.

(8) UNEP, Report of the Global Mercury Assessment Working Group on the Work of its First Meeting, Geneva, Switzerland, 2002.

(9) Loppi S., Bonini I.: Lichens and mosses as biomonitors of trace elements in areas with thermal springs and fumarole activity, Chemosphere, 2000, 41, 1333.

(10) Szynkowska M. I.: Scanning Electron Microscopy. Encyclopedia of Analytical Science, Second Edition, Vol. 4, Elsevier, Oxford, 2005.

(11) Kintz P.: Value of hair analysis in postmortem toxicology, Forensic Science International, 2004, 142, 127.

(12) Falandysz J., Jędrusiak A., Lipka K., Kannan K., Kawano M., Gucia M., Brzostowski A., Dadej M.: Mercury 
in wild mushrooms and underlying soil substrate from Koszalin, North-central Poland, Chemosphere, 2004, 54, 461.

(13) Grodzińska K., Szarek-Łukaszewska G., Godzik B.: Survey of heavy metal deposition in Poland using mosses as indicators, The Science of the Total Environment, 1999, 229, 41.

(14) Rautio P., Huttunen S., Total vs. internal element concentrations in Scots pine needles along a sulphur and metal pollution gradient, Environmental Pollution, 2003, 122, 273.

(15) Bettinelli M., Perotti M., Spezia S., Baffi C., Beone G. M., Alberici F., Bergonzi S., Bettinelli C., Cantarini P., Mascetti L.: The role of analytical methods for the determination of trace elements in environmental biomonitors, Microchemical Journal, 2002, 73, 131.

(16) Krupka K., Puczkowski S., Łaszczewska V.: Przemiana mineralna I analiza pierwiastkowa włosów w onkologii, Biomol- Laboratorium pierwiastków śladowych, Łódź, 2002.

(17) Polish statutory limits for $\mathrm{Hg}$ concentrations in dried mushrooms, Dziennik Ustaw, 37, 326, 2003. 